DOI: https://doi.org/10.47405/mjssh.v6i11.1148

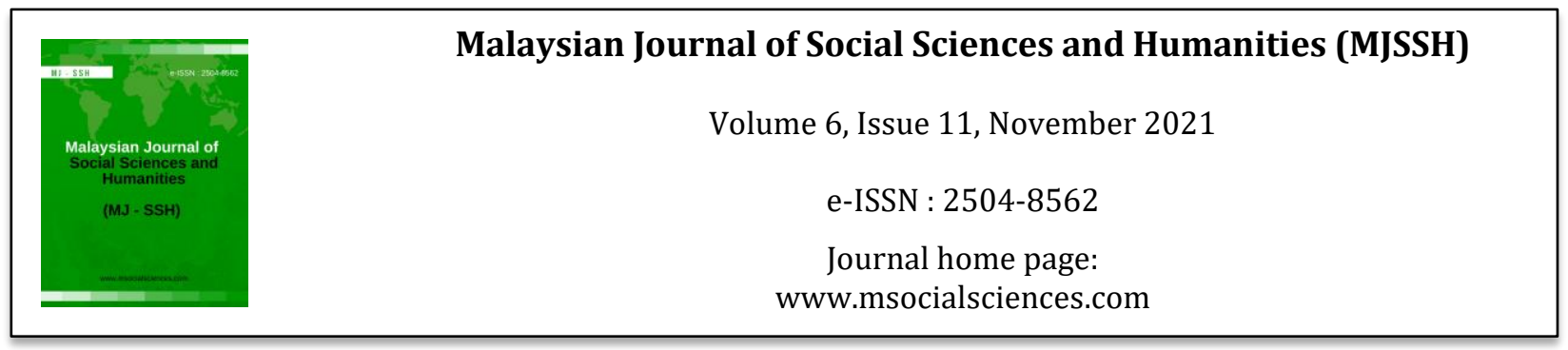

\title{
Pembinaan Instrumen Pencapaian Awal Matematik untuk Kanak-kanak Prasekolah
}

\author{
Connie Cassy Ompok ${ }^{1}$, Alley Emison ${ }^{1}$, Lydia Teo ${ }^{2}$ \\ ${ }^{1}$ Universiti Malaysia Sabah (UMS), Sabah, Malaysia \\ 2Institut Pendidikan Guru Kampus Keningau, Sabah, Malaysia \\ Correspondence: Connie Cassy Ompoka (connieompok@ums.edu.my)
}

\begin{abstract}
Abstrak
Kajian ini adalah membina instrumen untuk mengukur pencapaian awal matematik untuk kanak-kanak prasekolah. Dalam membina instrumen ini, penyelidik telah memilih kaedah konsistensi dalaman menggunakan Model Rasch. Dua set instrumen pencapaian awal Matematik kanak-kanak prasekolah diadaptasikan daripada Test of Early Mathematics Ability (TEMA) (Ginsburg dan Baroody, 2003) berdasarkan Kurikulum Standard Prasekolah Kebangsaan. Instrumen-instrumen ini merupakan ujian pra dan ujian pasca yang boleh digunakan untuk mengenal pasti kesan intervensi Matematik. Data kajian diperoleh melalui kaedah temu bual dan pemerhatian tulisan kanak-kanak yang seterusnya diterjemahkan kepada data kuantitatif. Kesemua item dalam kajian ini mempunyai kesahan konstruk iaitu berada dalam lingkungan 0.77 dan 1.30 semasa kajian rintis dijalankan.
\end{abstract}

Kata kunci: instrumen pencapaian awal matematik, kanak-kanak prasekolah, ketekalan dalaman

\section{Development of an Instrument to Measure Preschoolers' Early Mathematical Achievement}

\begin{abstract}
This study develop an instruments to measure early Mathematical achievement for preschool children. In developing the instruments, researchers have chosen the internal consistency method using the Rasch Model. Researchers developed two sets of early Mathematics achievement instruments for preschool children which are adapted from the Test of Early Mathematics Ability (TEMA) (Ginsburd and Baroody, 2003) and based on National Preschool Standard Curriculum. These instruments are pretest and post-test that can be used to identify the effects of Mathematics intervention. The data of study were obtained through interviews and observations of children's writing which were subsequently translated into quantitative data. All items in this study have construct validity that is in the range of 0.77 and 1.30 during the pilot study.
\end{abstract}

Keywords: early mathematical achievement instrument, preschool children, internal consistency

\section{Pengenalan}

Melihat kepada jurang pentaksiran Trends in International Mahematics and Science Study (TIMSS) antara negara Malaysia dan negara antarabangsa yang lain, telah membuka mata pelbagai pihak tentang 
pentingnya pendidikan Matematik di bidang pendidikan. Mengikut laporan TIMSS oleh Mullis, Martin, Kelly dan Fishbein (2020), penyertaan negara Malaysia dalam pentaksiran TIMSS pada tahun 2019 menunjukkan sedikit penurunan berbanding pencapaian Malaysia pada tahun 2015. Pada tahun 2019, Malaysia mendapat purata sebanyak 461 iaitu penurunan 4 purata berbanding purata pencapaian pada tahun 2015 iaitu sebanyak 465 (Mullis et al., 2020). Kajian Abdul Halim (2020) tentang pentaksiran PISA negara Malaysia menunjukkan peningkatan dalam pentaksiran PISA 2018, di mana Malaysia berada pada tempat kedua dalam kalangan Asia Tenggara dengan skor purata 440. Beliau turut menyatakan bahawa terdapat peningkatan yang signifikan bagi Literasi Matematik Malaysia iaitu sebanyak 13 mata berbanding PISA 2012. Menurut laporan OECD, bagi PISA 2018, terdapat 59\% pelajar Malaysia yang berada di aras 2 penguasaan Literasi Matematik.

Pendidikan prasekolah secara umumnya bertujuan untuk memberi pengalaman dan pendedahan pertama kepada kanak-kanak tentang pelbagai bentuk ilmu dan kemahiran asas sebagai persediaan mereka melangkah ke sistem pendidikan formal (Kurikulum Standard Prasekolah Kebangsaan, 2017; Mohd Nazri et al., 2021). Boleh dikatakan, latar belakang Matematik sebelum memasuki sekolah formal adalah kritikal untuk kejayaan pada masa hadapan (Jordan, 2010; Sarama et al., 2012). Pendidikan awal diperlukan untuk perkembangan kemahiran Matematik yang diperlukan di masa hadapan (Linder et al., 2011; Hunting et al., 2012) malah permulaan yang baik dalam mata pelajaran Matematik merupakan penentu kepada kejayaan pada masa akan datang di sekolah rendah, menengah mahupun di peringkat tinggi (Duncan et al., 2007). Melihat kepada kepentingan pendidikan Matematik untuk masa hadapan, program intervensi Matematik sejak kanak-kanak lagi perlu diberi penumpuan. Perhatian yang semakin meningkat oleh pendidik disebabkan oleh pengetahuan awal kanak-kanak yang sedang berkembang dan intervensi perlu dijalankan (Presser et al., 2015; Ompok et al., 2020; Ompok \& Bacotang, 2019; Ling, Pang \& Ompok, 2018; Ompok, Mei Teng \& Sapirai, 2021; Ompok et al., 2018; Ompok, Doig \& Tambagas, 2019).

Jika dilihat daripada kajian-kajian lepas berkaitan dengan pembinaan instrumen pencapaian awal Matematik untuk kanak-kanak prasekolah, kajian sedemikian masih kurang dijalankan mahupun di luar negara ataupun di dalam negara kita sendiri. Kanak-kanak mempunyai kebolehan Awal Matematik (Doig dan Ompok, 2010) tetapi alat untuk menaksir kebolehan awal Matematik untuk kanak-kanak belum dijumpai (Clements, Sarama \& Liu, 2008). Beberapa kajian dalam pembangunan instrumen telah dijalankan oleh Senocak et al. (2013) untuk menentukan pemahaman murid tadika tentang konsep Sains dan proses penyelidikan saintifik yang didasarkan pada Kurikulum prasekolah di Turki.

Berdasarkan daripada kajian-kajian lepas yang telah dijalankan, dapat dilihat bahawa penyelidikan seperti ini sangatlah membantu dalam meningkatkan lagi kualiti pengajaran dan pembelajaran serta menilai kemahiran murid sebagai penilaian untuk tujuan meningkatkan pencapaian kanak-kanak prasekolah bukan sahaja dalam awal Matematik tetapi dalam subjek-subjek yang lain juga (Senocak et al., 2013). Oleh itu, penyelidik digesa agar mengenal pasti terlebih dahulu instrumen yang boleh dipercayai dan mempunyai kesahan agar dapat menilai perkembangan dan pembelajaran yang berlaku dalam lima tahun pertama kehidupan kanak-kanak, seperti yang telah dinyatakan oleh Nor Mashitah et al. (2015).

\section{Objektif kajian}

Objektif kajian ini adalah untuk membina instrumen pencapaian awal Matematik untuk kanak-kanak prasekolah.

\section{Sorotan Literatur}

\section{Pencapaian Awal Matematik}

Mengikut Mix et al. (2002), fasa pemikiran Matematik dibahagikan kepada tiga fasa. Fasa pertama ialah fasa pra pengiraan (precounting phase). Fasa kedua ialah fasa pengiraan (counting phase) dan fasa 
ketiga ialah simbol yang bertulis (written number phase). Menurut Ginsburg dan Baroody (2003), kanak-kanak pada fasa pra pemikiran awal mulanya tidak menggunakan perkataan untuk berfikir tentang sesuatu himpunan dan bagaimana perubahan berlaku tetapi mereka mungkin menggunakan gambaran mental. Kanak-kanak boleh mengira himpunan objek-objek dengan tepat, boleh membina kefahaman asas nombor dan operasi penambahan dan penolakan walaupun sebelum memasuki sekolah. Kanak-kanak dalam lingkungan tiga setengah tahun sudah boleh mengingat dan menghasilkan semula himpunan objek dari satu hingga empat objek tanpa mengira. Pada usia tiga setengah hingga lima tahun, mereka boleh menunjukkan jumlah atau perbezaan apabila suatu bilangan item yang kecil ditambah atau ditolakkan dari objek sebelumnya yang dilihat. Menurut mereka lagi, kanak-kanak boleh menyelesaikan masalah penambahan dan penolakan yang mudah secara bukan lisan sebelum mereka berjaya melaksanakan masalah berbentuk cerita ataupun tugasan berbentuk simbolik seperti $2+1=$ ? Dalam fasa pengiraan, Mix et al. (2002) menyatakan bahawa kanak-kanak boleh menyatakan nombor secara lisan semasa mengira dalam perkataan (counting words). Pengetahuan Matematik yang tidak formal dapat dikembangkan melalui pengiraan. Apabila keupayaan Matematik kanak-kanak telah berkembang, mereka boleh menamakan koleksi nombor yang lebih besar daripada empat dan melakukan operasi terhadap nombor-nombor ini. Ginsburg dan Baroody (2003) menyatakan bahawa fasa nombor bertulis berkemungkinan dapat membantu kanak-kanak untuk berfikir dan mengoperasikan nombor yang lebih besar.

Gelman dan Gallistel (1978) berpendapat bahawa pemikiran kanak-kanak adalah konkrit dan abstrak. Bukan sahaja kanak-kanak boleh tambah tiga ekor anjing mainan dengan empat ekor anjing mainan untuk mendapatkan jumlah, mereka juga mempunyai idea yang abstrak dalam mengira termasuklah prinsip yang abstrak seperti peraturan mengira beberapa objek diskret. Mengikut Brush (1978), kanakkanak memahami idea asas tentang penambahan dan penolakan sejak di awal usia lagi. Kajian yang dijalankan oleh Wynn (1992) telah membuktikan kebolehan itu.

Ginsburg dan Baroody (2003) menyatakan bahawa pengetahuan Matematik kanak-kanak boleh dikategorikan sebagai tidak formal atau formal. Matematik tidak formal mewakili pengertian dan tatacara yang diperoleh di luar konteks persekolahan. Matematik formal mewakili kemahiran aritmetik dan konsep yang dipelajari oleh kanak-kanak di sekolah. Bagi Ginsburg dan Baroody (2003), kanakkanak sudah mempunyai konsep dan kemahiran yang tidak formal sebelum memasuki persekolahan. Situasi ini dipanggil sebagai tidak formal kerana mereka tidak belajar dalam konteks persekolahan yang formal. Kefahaman ini selalunya bersifat implisit. Seorang kanak-kanak berkemungkinan tidak berkebolehan untuk menerangkan mengapa dia menggunakan sesuatu strategi tidak formal atau mengapa jawapannya adalah munasabah. Konsep dan kemahiran ini diperoleh dalam pelbagai cara. Satu caranya ialah inisiatif oleh kanak-kanak itu sendiri atau interaksi dengan persekitaran mereka. Sebagai contoh, ibu memberitahu anak-anak bahawa setiap kumpulan yang mempunyai tiga orang kanak-kanak mestilah mempunyai jumlah gula-gula yang sama. Terdapat sebanyak sepuluh biji gula-gula yang harus dibahagikan kepada tiga orang kanak-kanak. Maka dalam aktiviti ini, kanak-kanak berpeluang untuk mempelajari konsep lebih, kurang atau sama banyak. Mereka juga akan mengambil inisiatif mengira himpunan untuk menghasilkan jumlah gula-gula yang sama dengan melibatkan aktiviti menambah atau menolak dengan menggunakan kemahiran yang tidak formal.

Dalam pengetahuan Matematik formal, Ginsburg dan Baroody (2003) menyatakan kanak-kanak diajar dengan nombor-nombor dan kemahiran aritmetik, termasuk simbol bertulis. Sebagai contoh, nombor 7 mewakili nombor, dan tanda + atau - mewakili operasi terhadap sesuatu nombor. Kanak-kanak mencuba untuk menguasai fakta nombor seperti $7+3=10$.

Berbanding dengan pengetahuan yang tidak formal, Ginsburg dan Baroody (2003) menyatakan pengetahuan konsep formal memerlukan kefahaman yang eksplisit iaitu kanak-kanak seharusnya dapat menerangkan secara rasional tatacara dan memberikan justifikasi terhadap sesuatu jawapan. Oleh itu, kunci asas dalam mentaksir pengetahuan formal adalah mengenal pasti sama ada kanak-kanak boleh menerangkan dan memberikan justifikasi tatacara secara eksplisit. Namun begitu, kebanyakan kanakkanak terlepas peluang belajar tentang pengetahuan Matematik di luar konteks persekolahan kerana persekitaran yang kurang menyokong. 
Berdasarkan kepada perbincangan tentang awal Matematik oleh Mix et al. (2002), Ginsburg dan Baroody (2003), Gelman dan Gallistel (1978), Brush (1978) dan Griffin et al. (1994), pencapaian awal Matematik dalam kajian ini merujuk kepada awal nombor. Perbincangan-perbincangan melalui perenggan sebelumnya juga menekankan kepada aspek pengetahuan, kefahaman dan kemahiran dalam nombor.

\section{Metod Kajian}

\section{Kebolehpercayaan instrumen}

Kebolehpercayaan dalam sesuatu penyelidikan merujuk kepada keupayaan suatu kajian untuk memperoleh nilai yang serupa apabila pengukuran yang sama diulangi. Kebolehpercayaan bermakna konsistensi instrumen dalam mengukur sesuatu tugasan (Wiersma, 1995). Menurut Chua (2009), kaedah yang digunakan untuk membina kebolehpercayaan pengukuran dalam penyelidikan kuantitatif terdiri daripada tiga kaedah iaitu ujian pra-pasca (test-retest), kaedah pemisahan separa ujian dan kaedah konsistensi dalaman. Penyelidik telah memilih kaedah konsistensi dalaman (internal consistency method) menggunakan Model Rasch untuk mengukur kebolehpercayaan instrumen yang digunakan semasa kajian rintis.

\section{Alat Pengukuran}

Kajian ini membina Ujian Pencapaian Awal Matematik. Cates (1990) mendefinisikan instrumen kajian atau alat pengukuran sebagai alat yang digunakan untuk mengumpul data kajian berkaitan responden. Dalam kajian ini, penyelidik telah membina dua set instrumen pencapaian awal Matematik kanak-kanak prasekolah yang diadaptasikan daripada Test of Early Mathematics Ability (TEMA) (Ginsburg \& Baroody, 2003) berdasarkan KSPK. Instrumen-instrumen ini merupakan ujian pra dan ujian pasca yang boleh digunakan untuk mengenal pasti kesan intervensi. Data-data penyelidikan diperoleh melalui kaedah temu bual dan pemerhatian tulisan kanak-kanak yang seterusnya diterjemahkan kepada data kuantitatif.

TEMA-1 telah diperkenalkan pada tahun 1983. Ujian ini direka khas untuk kanak-kanak yang berumur antara empat tahun (4-0) sehingga lapan tahun sebelas bulan (8-11) dan ditadbirkan secara individu. Ujian ini mengandungi 50 soalan. Borang A digunakan untuk ujian pra dan borang B digunakan untuk ujian pasca. Pada tahun 1990, TEMA-2 telah dihasilkan setelah penambahbaikan dijalankan pada TEMA-1. TEMA-2 mempunyai kekuatan dalam mengenal pasti, meneroka kemahiran Matematik dan proses penaakulan kanak-kanak. Seterusnya, TEMA-3 dihasilkan pada tahun 2003 dalam memenuhi keperluan satu instrumen yang menunjukkan kepercayaan dan kesahan dalam mengenal pasti kebolehan awal Matematik kanak-kanak. TEMA-3 yang dibina menggunakan permainan, gambar dan lembaran kerja dalam mengendalikan ujian.

Penyelidik bersama dengan tiga guru pendidikan awal kanak-kanak iaitu guru dari prasekolah KPM dan tadika KEMAS telah membuat penyemakan ke atas 72 soalan yang terdapat dalam TEMA-3. Satu kriteria yang harus dipatuhi dalam memilih soalan UPAM yang digunakan dalam kajian ini ialah soalan TEMA-3 yang asal haruslah bersesuaian dengan kandungan Matematik yang terdapat dalam KSPK iaitu pengalaman pra nombor, konsep nombor yang merangkumi nombor 1 hingga 20, siri 10, 20, 30, 40 dan 50, dan operasi tambah dan tolak dalam lingkungan 10 (KPM, 2010). Penyelidik tidak mengubah urutan soalan dari soalan TEMA-3 yang asal.

Setelah membuat penyemakan, didapati hanya terdapat 31 soalan TEMA-3 yang memenuhi KSPK. Sekiranya penyelidik memilih hanya 31 soalan, soalan tentang memahami siri 10, 20, 30, 40 dan 50, dan operasi tambah dan tolak dalam lingkungan 10 tidak dapat dimasukkan. Namun penyelidik mendapati bahawa sebanyak sembilan soalan dalam urutan TEMA-3 boleh diubahsuai untuk menjadikan instrumen ini merangkumi soalan tentang memahami siri 10, 20, 30, 40 dan 50, dan juga operasi tambah dan tolak dalam lingkungan 10. 
Pengubahsuaian ke atas instrumen ini mengambil kira cadangan-cadangan yang berikut. Pertama, guruguru prasekolah yang berpengalaman mencadangkan agar beberapa rangsangan di dalam alat ukur digantikan kerana terdapat rangsangan yang tidak begitu biasa (familiar) bagi kanak-kanak tempatan. Rangsangan seperti gambar haiwan telah diubahsuai mengikut suasana di Malaysia dalam soalan A1 dan B1 (persepsi nombor ringkas) dan A18 dan B18 (set representasi bertulis hingga 5). Nama orang barat telah digantikan dengan nama orang Malaysia dalam soalan A25 dan B25 (pembahagian sama rata: perkongsian sama rata bagi kuantiti diskret) dan A31 dan B31 (pengiraan terus daripada penambahan yang lebih besar).

Kedua, penyelidik juga telah mengubah sembilan soalan TEMA-3 yang asal agar memenuhi kandungan Matematik yang terdapat dalam KSPK. Bagi soalan A21 dan B21 (pengiraan satu-satu secara lisan), penyelidik telah menukar soalan asal iaitu kira hingga 40 kepada kira hingga 20. Bagi soalan A22 dan B22 (nombor selepas: nombor dua digit), penyelidik telah menukar nombor dua digit hingga 40 kepada nombor dua digit hingga 20. Bagi soalan A29 dan B29 (menulis angka: nombor dua digit), penyelidik telah menukar nombor dua digit yang kurang daripada 100 kepada nombor dua digit dari 10 hingga 20. Bagi soalan A30 dan B30 (mengira satu-satu secara lisan), penyelidik telah menukar kira bermula 10 hingga 42 kepada kira bermula 10 hingga 20. Bagi soalan A32 dan B32 (pengiraan sepuluh-sepuluh secara lisan), penyelidik telah menukar kira sepuluh-sepuluh hingga 90 kepada kira sepuluh-sepuluh hingga 50. Bagi soalan A33 dan B33 (penambahan ketukartertiban secara simbolik), penyelidik telah menukar nama orang barat kepada orang Malaysia dan ayat nombor yang memberikan jumlah dalam lingkungan 10. Bagi soalan A34 dan B34 (membaca angka: nombor dua digit), penyelidik telah menukarkan membaca nombor dua digit di atas 20 kepada membaca nombor sepuluh-sepuluh hingga 50. Bagi soalan A35 dan B35 (garis nombor dalam fikiran: nombor dua digit), penyelidik telah menukarkan nombor dua digit yang lebih daripada 20 kepada nombor dua digit iaitu dari nombor 10 hingga 20. Bagi soalan 40 (pengiraan empat-empat secara lisan: hingga 20), penyelidik telah menukar pengiraan empat-empat hingga 40 secara lisan kepada pengiraan secara dua-dua hingga 10.

Setelah alat ukur ini diubahsuai dengan mengambil kira cadangan guru dan penyelidik, lima orang pakar pendidikan awal kanak-kanak diminta menilainya dari segi kesahan kandungan dan konstruk. Pakar pendidikan awal kanak-kanak yang dirujuk bersetuju bahawa alat ukur tersebut mempunyai kesahan kandungan dan kesahan konstruk. Bagi kesemua item instrumen berkenaan, item asal dalam Bahasa Inggeris diterjemahkan sepenuhnya ke dalam Bahasa Malaysia. Seterusnya, instrumen ini disemak oleh penterjemah dari Institut Terjemahan Negara Malaysia untuk memastikan penggunaan istilah Matematik yang tepat. Setelah pengubahsuaian dijalankan, terdapat sebanyak 40 soalan yang perlu dijawab oleh responden untuk tujuan kajian ini. Bukan sahaja jumlah 40 soalan memenuhi KSPK, malah jumlah ini memudahkan pengiraan skor dan juga kesesuaian masa yang diperuntukkan dalam 30 minit. Alat ukur yang baharu ialah Ujian Pencapaian Awal Matematik (UPAM).

Ujian pra (A) dan ujian pasca (B) yang dibina dan dianalisis mempunyai standard yang sama. Senarai soalan UPAM yang telah dikenal pasti dan dipilih adalah seperti berikut: A1 dan B1 ialah persepsi nombor ringkas (tidak formal). A2 dan B2 ialah menunjukkan paparan jari: 1, 2, banyak (tidak formal). A3 dan B3 ialah pengiraan satu-satu secara lisan: 1 hingga 5 (tidak formal). A4 dan B4 ialah persepsi terhadap lebih banyak: hingga 10 item (tidak formal). A5 dan B5 ialah penghasilan bukan lisan: 1 hingga 4 item (tidak formal). A6 dan B6 ialah pengangkaan: 1 hingga 5 item (tidak formal). A7 dan B7 ialah peraturan kekardinalan (tidak formal). A8 dan B8 ialah penambahan dan penolakan bukan lisan (konkrit) (tidak formal). A9 dan B9 ialah kemalaran nombor (tidak formal). A10 dan B10 ialah menghasilkan set: hingga 5 item (tidak formal). A11 dan B11 ialah menunjukkan paparan jari hingga 5 (tidak formal). A12 dan B12 ialah pengiraan satu-satu secara lisan: 1 hingga 10 (tidak formal). A13 dan B13 ialah nombor selepas: 1 hingga 9 (tidak formal). A14 dan B14 ialah membaca angka: nombor satu digit (formal). A15 dan B15 ialah menulis angka: nombor satu digit (formal). A16 dan B16 ialah memberi contoh masalah penambahan melalui perkataan dengan jelas: jumlah hingga 9 (tidak formal). A17 dan B17 ialah konsep bahagian-keseluruhan (tidak formal). A18 dan B18 ialah set representasi bertulis hingga 5 (formal). A19 dan B19 ialah memilih nombor yang lebih besar: perbandingan nombor 1 hingga 5 (tidak formal). A20 dan B20 ialah memilih nombor yang lebih besar: perbandingan nombor 5 hingga 10 (tidak formal). A21 dan B21 ialah pengiraan satu-satu secara lisan: hingga 20 (tidak formal). A22 dan B22 ialah nombor selepas: nombor dua digit (tidak formal). A23 dan B23 ialah 
pengangkaan: 6 hingga 10 item (tidak formal). A24 dan B24 ialah kiraan secara terbalik daripada 10 secara lisan (tidak formal). A25 dan B25 ialah pembahagian sama rata: perkongsian sama rata bagi kuantiti diskret (tidak formal). A26 dan B26 ialah penambahan dalam fikiran: jumlah 5 hingga 9 (tidak formal). A27 dan B27 ialah garis nombor dalam fikiran: nombor satu digit (tidak formal). A28 dan B28 ialah membaca angka: nombor 10 hingga 20 (formal). A29 dan B29 ialah menulis angka: nombor dua digit (formal). A30 dan B30 ialah mengira satu-satu secara lisan bermula daripada 10: hingga 20 (tidak formal). A31 dan B31 ialah pengiraan terus daripada penambahan yang lebih besar (tidak formal). A32 dan B32 ialah pengiraan sepuluh-sepuluh secara lisan: hingga 50 (tidak formal). A33 dan B33 ialah penambahan ketukartertiban secara simbolik (formal). A34 dan B34 ialah membaca angka: nombor dua digit (formal). A35 dan B35 ialah garis nombor dalam fikiran: nombor dua digit (tidak formal). A36 dan B36 ialah fakta penolakan: $\mathrm{N}-\mathrm{N}$ dan $\mathrm{N}-1$ (formal). A37 dan B37 ialah fakta penambahan: jumlah hingga 9 (formal). A38 dan B38 ialah fakta penambahan: jumlah dalam lingkungan 10 dan gandaan kecil. A39 dan B39 ialah fakta penolakan: 10 - N (formal). A40 dan B40 ialah pengiraan dua-dua secara lisan: hingga 10 (tidak formal).

Penyelidik menggunakan borang skor markah semasa mengendalikan ujian ini. Borang skor markah terbahagi kepada dua bahagian, iaitu Bahagian A dan Bahagian B. Bahagian A mengandungi maklumat berkaitan dengan latar belakang responden. Bahagian B pula terdiri daripada 40 soalan UPAM. Ujian ini ditadbirkan secara individu. Penyelidik membacakan stimuli soalan beserta bahan-bahan sekiranya diperlukan seperti token, gambar dan lembaran kerja semasa sesi ujian. Skor 1 diberikan sekiranya dapat menjawab soalan dan skor 0 jika sebaliknya. Untuk mendapat skor satu markah, semua bahagian dalam satu soalan mesti dijawab dengan betul. Misalnya, soalan satu mengandungi tiga bahagian iaitu (a), (b) dan (c). Untuk mendapat skor sebanyak satu markah, kriteria skor seperti yang dinyatakan dalam borang skor markah iaitu 3/3 haruslah dipenuhi. Dalam contoh yang lain, jika suatu soalan mempunyai kriteria skor iaitu 4/6, empat bahagian daripada mana-mana enam bahagian dalam soalan tersebut mestilah dijawab dengan betul.

Terdapat beberapa persediaan yang diikuti sebelum mentadbir ujian kepada kanak-kanak. Pertama, arahan soalan perlu difahami oleh penyelidik sebelum ujian ditadbirkan. Kedua, penyelidik perlu memastikan jawapan yang betul bagi soalan yang dikemukakan bagi memendekkan masa mentadbirkan semua soalan. Ketiga, penyelidik perlu memastikan cara bagaimana skor dikira dan direkodkan bagi setiap soalan. Manual dan arahan-arahan perlu dibaca beberapa kali bagi setiap soalan, diikuti pula dengan demonstrasi. Keempat, penyelidik perlu mengenal pasti bahan yang diperlukan dan memberi token sebagai pembilang apabila diperlukan semasa mengendalikan ujian.

Semasa pentadbiran instrumen, penyelidik telah mengambil beberapa langkah. Pertama, data peribadi semua kanak-kanak di kelas telah diisi dalam borang skor markah. Kedua, kanak-kanak yang diuji dipastikan berada dalam keadaan selesa dan selamat. Ketiga, seorang kanak-kanak dipanggil mengikut senarai nama seperti dalam buku kehadiran. Keempat, penyelidik duduk berhadapan dengan kanakkanak. Sebuah meja diletakkan di antara penyelidik dan kanak-kanak semasa ujian dijalankan. Kelima, ujian dimulakan dengan berkata, "kita hendak menjawab soalan Matematik. Senang sahaja. (sebut nama kanak-kanak) cuba buat yang terbaik". Penyelidik mengulangi arahan sekali lagi jika kanak-kanak didapati masih tidak memahami arahan. Keenam, ganjaran dalam bentuk pujian diberi kepada kanakkanak dari semasa ke semasa seperti, "bagus, (nama kanak-kanak disebut) rajin belajar" dan sebagainya. Ketujuh, jawapan kanak-kanak dibandingkan dengan gerak balas yang betul seperti dalam borang skor markah.

\section{Kesahan Alat Ukur}

Bailey (1996) menyatakan bahawa sesuatu alat ukur yang digunakan bagi mengumpul data berkaitan sampel kajian iaitu sejauh mana perbezaan markah pencapaian mencerminkan perbezaan sebenar pemboleh ubah yang hendak diukur. Alat ukur yang digunakan ialah ujian yang ditadbirkan pada awal kajian yang dikenali sebagai ujian pra dan ujian yang diadakan pada akhir kajian dikenali sebagai ujian pasca.

Alat ukur yang digunakan dalam kajian ini telah mengambil kira cadangan guru dan lima orang pakar 
pendidikan awal kanak-kanak yang telah menilainya dari segi kesahan kandungan dan konstruk. Pakar pendidikan awal kanak-kanak yang dirujuk bersetuju bahawa alat ukur tersebut mempunyai kesahan kandungan. Kesemua item dalam kajian ini mempunyai kesahan konstruk iaitu berada dalam lingkungan 0.77 dan 1.30 semasa kajian rintis dijalankan. Semua perkara ini telah diambil kira dalam kajian ini. Semua item UPAM dapat difahami oleh kanak-kanak dengan baik. Tambahan pula, susunan ayat-ayat dalam soalan item UPAM awal Matematik mudah difahami.

\section{Kajian Rintis}

Kajian rintis merupakan kajian kecil-kecilan yang dilakukan sebelum kajian sebenar dilakukan. Kajian rintis dijalankan untuk menguji kesesuaian alat ukur yang digunakan dalam kajian ini.

Tujuan kajian rintis dijalankan adalah untuk :

i. Mengenal pasti masalah berhubung pemahaman dan interpretasi responden terhadap item-item ujian pra dan ujian pasca.

ii. Mendapat maklum balas daripada jawapan mereka yang dijadikan sebagai asas untuk memurnikan item tersebut.

iii. Menilai proses kajian yang dijalankan agar kajian sebenar dapat dijalankan dengan lancar.

Kajian rintis untuk instrumen yang digunakan dijalankan ke atas 136 orang kanak-kanak yang belajar di tadika KEMAS dan prasekolah KPM. Analisis data menggunakan Model Item Respon (Bond \& Fox, 2001).

\section{Hasil Kajian}

Analisis ketekalan dalaman menunjukkan bahawa instrumen ini mempunyai kebolehpercayaan yang tinggi. Kebolehpercayaan pada ujian pra ialah 0.87. Manakala bagi ujian pasca pula, kebolehpercayaannya ialah 0.882 tetapi meningkat kepada 0.883 apabila item 4 dibuang.

Rajah 1 menunjukkan item fit map ujian pra. Item 1 didapati tidak terdapat dalam item fit map kerana semua responden telah mendapat skor 1 pada soalan ini. Dalam Rajah 2 pula, item 1 tidak terdapat dalam item fit map dan item 4 berada di luar lingkungan nilai infit mean square 0.77 hingga 1.30. Menurut Pang (2005), item yang berada di luar lingkungan perlu disemak pada ayat ataupun arahanarahan yang kurang jelas, pengubahsuaian ataupun dibuang.

\section{Ujian Pra}

Rajah 1: Item Fit Map pada ujian pra

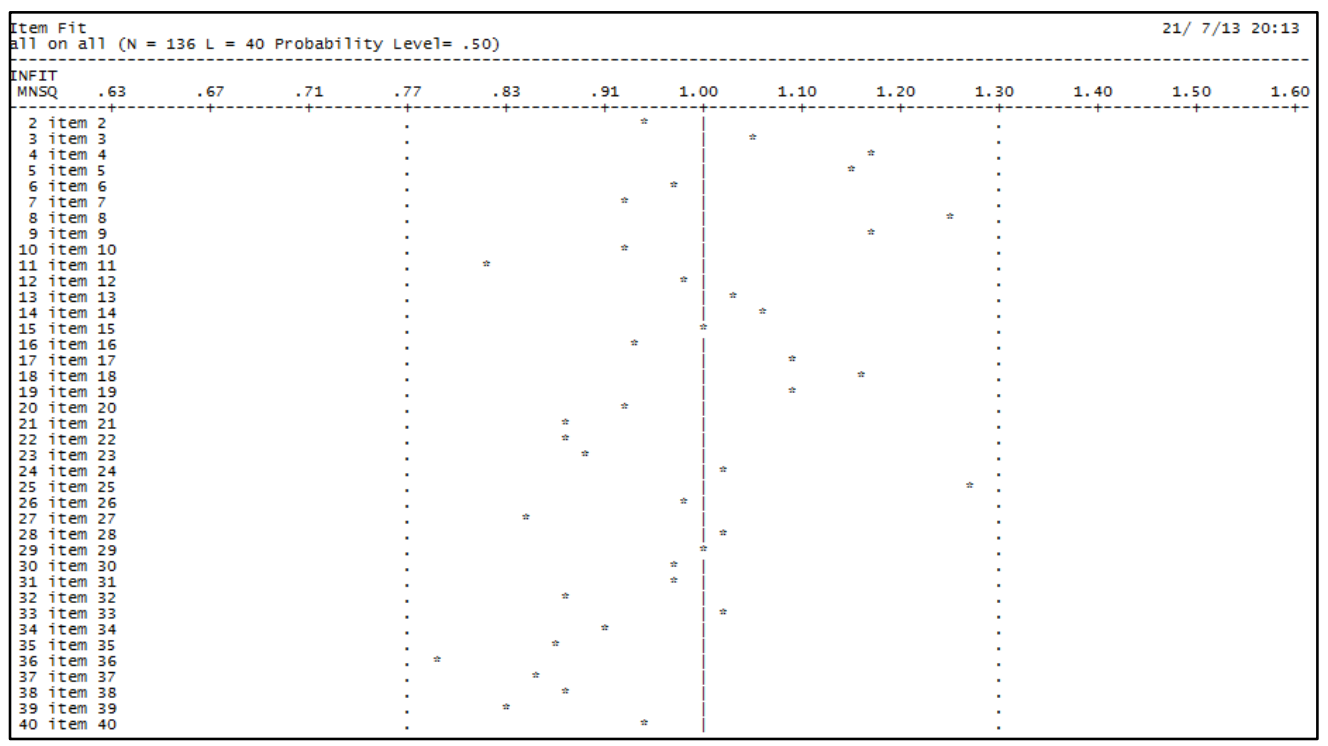




\section{Ujian Pasca}

Rajah 2: Item Fit Map pada ujian pasca.

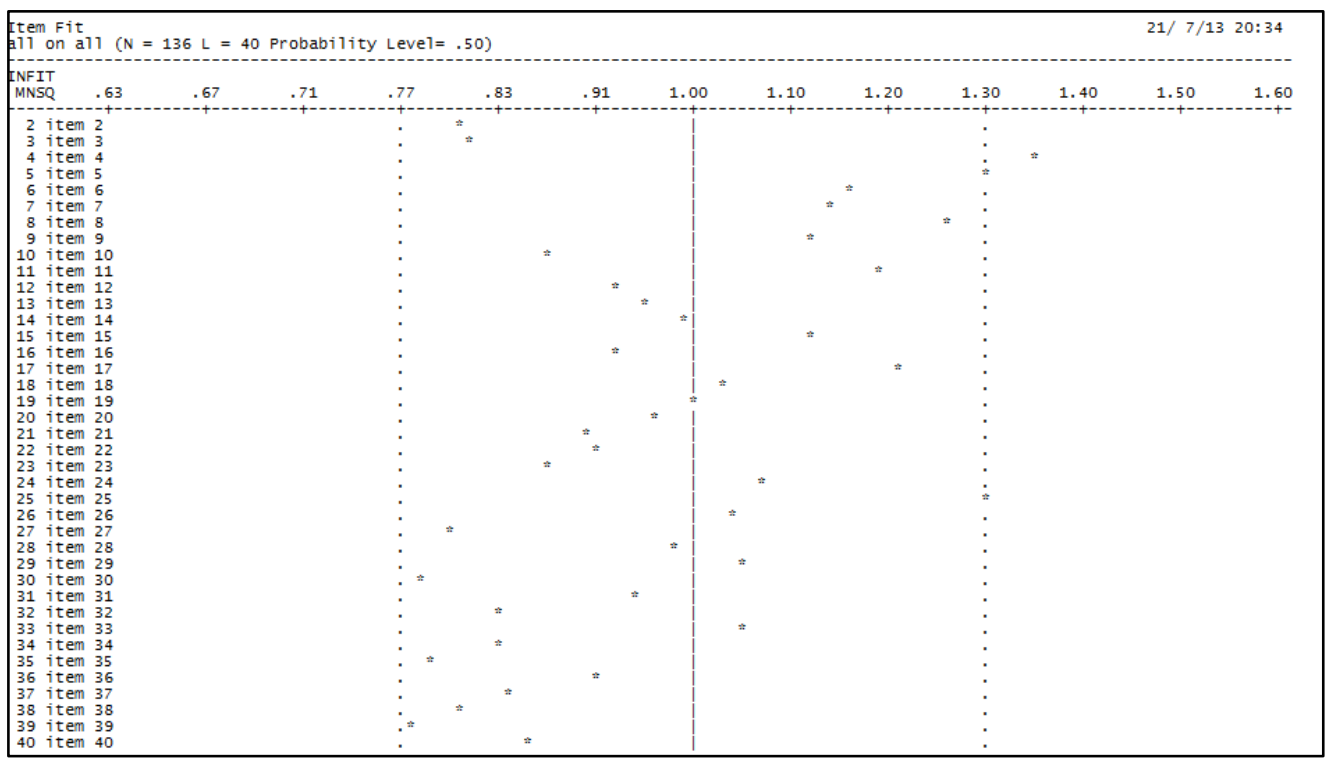

\section{Kesimpulan}

Penyelidik telah mengambil keputusan untuk mengubahsuai item A1, A4, B1 dan B4 dalam kajian yang sebenar. Bahan yang beraneka warna membantu kanak-kanak mengira. Terdapat kanak-kanak yang lebih menumpukan perhatian kepada bahan berwarna-warni berbanding dengan soalan yang dikemukakan oleh penyelidik untuk dijawab. Masa dalam lingkungan 30 minit untuk menghabiskan soalan yang harus ditanya kepada seorang kanak-kanak. Untuk memendekkan masa mengendalikan UPAM, penyelidik perlu memahami soalan yang dikemukakan kepada kanak-kanak dan kemudiannya membacakan stimuli yang terdapat dalam borang skor murid. Namun, masa untuk menjalankan ujian kepada kanak-kanak adalah fleksibel (Ginsburg \& Baroody, 2003). Ini bermakna, ujian boleh diteruskan pada keesokan harinya jika didapati kanak-kanak tidak selesa. Penyelidik juga mendapati bahawa kanak-kanak lain suka mengganggu rakannya yang sedang menjalani ujian. Oleh itu, ujian dikendalikan dalam bilik tertutup untuk mengelakkan gangguan. Jika ujian yang dijalankan juga bertujuan untuk pengajaran dan pembelajaran bagi memastikan kanak-kanak dapat menguasai suatu soalan, penyelidik mengambil masa yang lama untuk menyiapkan ujian. Ini menyebabkan kanak-kanak yang sedang diuji berasa bosan. Maka dengan itu, adalah dicadangkan kepada guru untuk berhenti bertanya soalan sekiranya mendapati tiada pengiraan dibuat oleh kanak-kanak dalam masa tiga saat. Penyelidik juga mendapati bahawa kanak-kanak merasa bosan sekiranya menggunakan lembaran kerja yang berwarna hitam putih. Mereka mengatakan, "ini sajakah cikgu, bosan sudah". Setelah mengambil kira semua ini, penyelidik telah menjadikan semua lembaran kerja berwarna-warni untuk menarik perhatian kanakkanak. Ujian Pencapaian Awal Matematik yang dibina mempunyai ketekalan dalaman yang tinggi. Kanak-kanak mempunyai pemikiran awal Matematik yang tinggi tetapi mereka mungkin belum mempunyai kebolehan menulis apa yang difikirkan. Instrumen yang dihasilkan boleh digunakan untuk mengukur kesan intervensi yang dijalankan.

\section{Rujukan}

Abdul Halim, A. (2020). Pentaksiran PISA: Di Mana Kedudukan Malaysia Untuk Literasi Matematik Dalam Kalangan Negara Asia Tenggara.

Bailey, C. A. (1996). A guide to field research. Thousand Oaks: Pine Forge Press. 
Bloom, B. S. (1956). Taxonomy of Educational Objectives, the classification of educational goals Handbook I: Cognitive Domain. New York: McKay.

Bond, T. G., \& Fox, M. C. (2001). Applying the Rasch model fundamental measurement in the human Science. ( $2^{\text {nd }}$ edition). London: Lawrance Erlbaum Association Publishers.

Brush, L. R. (1978). Preschool children's knowledge of addition and subtraction. Journal for Research in Mathematics Education. 9:44-54.

Cates, W. M. (1990). Panduan amali untuk penyelidikan pendidikan. Penterjemah: Syaharom Abdullah. K uala Lumpur: Dewan Bahasa dan Pustaka.

Chua, Y. P. (2009). Statistik penyelidikan lanjutan: Ujian univariat dan multivariat. Shah Alam: McGraw-Hill.

Clements, D., Sarama, J., \& Liu, X. (2008). Development of a measure of early mathematics achievement using the Rasch model: the ResearchBased Early Maths Assessment. Educational Psychology, 28(4), 457-482.

Duncan, G. J., Dowsett, C. J., Claessens, A., Magnuson, K., Huston, A. C., Klebanov, P., Pagani, L., Feinstein, L., Engel, M., Brooks-Gunn, J., Sexton, H., Duckworth, K., \& Japel, C. (2007). School readiness and later achievement. Developmental Psychology. 43, 1428-1446.

Doig, B., \& Ompok, C. S. (2010). Assessing young children's Mathematical abilities through games. Procedia-Social and $\quad$ Behavioral 228-235. https://scholar.google.com/citations?view_op=view citation\&hl=en\&user=B5XCKF4AAAAJ\&cit ation for view=B5XCKF4AAAAJ:u5HHmVD uO8C

Gelman, R., \& Gallistel, C. R. (1978). The child's understanding of number. Cambridge, MA: Harvard University Press.

Ginsburg, H. P., \& Baroody, A. J. 2003. Test of early Mathematics ability (3 ${ }^{\text {rd }}$ edition) Austin: PRO-ED SAGE Publications.

Griffin, S., Case, R., \& Siegler, R. (1994). Rightstart: Providing the central conceptual prerequisites for first formal learning of arithmetic to students at-risk for school failure. In McGilly, K. (Ed.). Classroom Lessons: Integrating cognitive theory and classroom practive, pp. 24-49. Cambridge, MA: Bradford Books MIT Press.

Hunting, R., Mousley, J., \& Perry, B. (2012).Young children learning Mathematics: A guide for educators and families. Melbourne, Vic.: ACER press.

Jordan, N. C. (2010). Early predictors of Mathematics achievement and Mathematics learning difficulties. In Tremblay, R. E., Barr, R. G., Peters, R. DeV., \& Boivin, M. (Ed.) Encyclopedia on Early Childhood Development, pp. 1-6. Montreal, Quebec.

Kementerian Pendidikan Malaysia. (2017). Kurikulum Standard Prasekolah Kebangsaan. Kuala Lumpur: Bahagian Pembangunan Kurikulum.

Kementerian Pendidikan Malaysia. (2013). Laporan Awal. Pelan Pembangunan Pendidikan Malaysia 2013-2025. Kuala Lumpur: Bahagian Perancangan dan Penyelidikan Dasar Pendidikan.

Linder, S. M., Powers-Costello, B., \& Stegelin, D. A. (2011). Mathematics in early childhood:Researchbased rationale and practical strategies. Early Childhood Education Journal, 39:29-37.

Ling MT., Pang V., \& Ompok C. S. (2018) Measuring Change in Early Mathematics Ability of Children Who Learn Using Games: Stacked Analysis in Rasch Measurement. In: Zhang $Q$. (eds) Pacific Rim Objective Measurement Symposium (PROMS) 2016 Conference Proceedings. Springer, Singapore. https://doi.org/10.1007/978-981-10-8138-5_17.

Mix, K. S., Huttenlocher, J., \& Levine, S. C. (2002). Quantitative development in infancy and early childhood. New York: Oxford University Press.

Mohd Nazri, A, R., Muhamad Ikhwah, M, S., Abu Bakar, M., \& Md. Nazri, A, R. (2021). Aplikasi pendekatan Interpretive Structural Modeling (ISM) dalam pembangunan Model Pengurusan Pentaksiran kanak-kanak prasekolah. Southeast Asia Early Childhood Journal, 10.

Mullis, I. V. S., Martin, M. O., Foy, P., Kelly, D. L., \& Fishbein, B. (2020). TIMSS 2019 International Results in Mathematics and Science. Retrieved from Boston College, TIMSS \& PIRLS International Study Center.

Nor Mashitha M, R., Mariani, M, N., Jain, C., \& Che' Mah, Y. (2015). Developing a Measure of Authentic Assessment Standard for Children Development and Learning Using Many-Facet Rasch Model. Southeast Asia Early Childhood Journal, 4, 17-30. 
Ompok, C. S. (2015). Kesan penggunaan kaedah permainan, buku nombor dan lembaran kerja terhadap pencapaian awal Matematik dalam kalangan kanak-kanak prasekolah kebangsaan. Thesis Ijazah Doktor Falsafah UMS. https://scholar.google.com/citations?view_op=view_citation\&hl=en\&user=B5XCKF4AAAAJ\&cit ation for view=B5XCKF4AAAAJ:3fE2CSJIr18C

Ompok, C. S., Ling, M. T., Abdullah, S. N. M. @ S., Tambagas, M., Tony, E. E., \& Said, N. (2020). Mentor-mentee programme for STEM education at preschool level. Southeast Asia Early Childhood Journal,9(1), 1-14. $\quad$ Retrieved from https://ejournal.upsi.edu.my/index.php/SAECJ/article/view/3147.

Ompok, C. S., \& Bacotang, J. (2019). Kesan kaedah mengajar terhadap pencapaian awal matematik dalam kalangan kanak-kanak prasekolah. Jurnal Pendidikan Awal Kanak-Kanak Kebangsaan, 8, 816. https://doi.org/10.37134/jpak.vol8.2.2019.

Ompok, C. S., Mei Teng, L., \& Sapirai, J. (2021). Effect of games towards children's mathematics performance. Southeast Asia Early Childhood Journal, 10(1), 1-17. https://doi.org/10.37134/saecj.vol10.1.1.2021.

Ompok, C. S., Teng, L., Pang, V., Mun, H., Abdullah, A., \& Sapirai, J. (2018). Early mathematics learning in reading and writing numerals: Learning through "What are the numbers?" A picture book made up of Flora and Fauna in Borneo. Southeast Asia Early Childhood Journal, 7, 52-59. https://doi.org/10.37134/saecj.vol7.6.2018.

Ompok, C. S., Doig, B., \& Tambagas, M. (2018). Patterns of Young Children's Number Sense Development as Assessed by How Many Hidden Game. Journal of Cognitive Sciences and Human Development, 4(2), 12-17. https://doi.org/10.33736/jcshd.1117.2018.

Sarama, J., Lange, A. A., Clements, D. H., \& Wolfe, C. B. (2012). The impacts of an early Mathematics curriculum on oral language and literacy. Early Childhood Research Quarterly. 27:489-502.

Senocak, E., Aksoy, P., Samarapungavan, A., \& Tosun, C. (2013). A Study on Development an Instrument to Determine Turkish Kindergarten Students' Understanding of Scientific Concept and Scientific Inquiry Processes. Educational Sciences: Theory and Practices, 13(4), 2217-2228.

Stadler-Altmann, U. (2015). Learning Environment: The Influence of School and Classroom Space on Education. In book: The Routledge International Handbook of Social Psychology of the Classroom, pp 252-262.

Pang, V. (2005). Curriculum Evaluation. An application in a smart school curriculum implementation. Kota Kinabalu: University Malaysia Sabah.

Presser, A. L., Clements, M., Ginsburg, H., \& Ertle, B. (2015). Big Math for little kids: The effectiveness of a preschool and kindergarten Mathematics curriculum. Early Education and Development. 26(3):399-426.

Wiersma, W. (1985). Research method in education an introduction (6 ${ }^{\text {th }}$ Edition). New York: A Simon and Shuster Company.

Wynn, K. (1992). Addition and subtraction by human infants. Nature. 358:749-750. 